\title{
Unique patterns of dietary adequacy in three cultures of Canadian Arctic indigenous peoples
}

\author{
Harriet V Kuhnlein ${ }^{1,2, *}$, Olivier Receveur ${ }^{3}$, Rula Soueida ${ }^{1}$ and Peter R Berti ${ }^{4}$ \\ ${ }^{1}$ Centre for Indigenous Peoples' Nutrition and Environment (CINE), McGill University, Macdonald Campus, \\ 21110 Lakeshore Road, Ste. Anne de Bellevue, Quebec, Canada, H9X 3V9: ${ }^{2}$ School of Dietetics and Human \\ Nutrition, McGill University, Ste. Anne de Bellevue, Quebec, Canada: ${ }^{3}$ Department of Nutrition, University of \\ Montréal, Montréal, Quebec, Canada: ${ }^{4}$ HealthBridge, Ottawa, Ontario, Canada
}

Submitted 27 October 2006: Accepted 3 April 2007: First published online 5 July 2007

\begin{abstract}
Background: Information is needed on dietary adequacy of Arctic indigenous populations in Canada. Extensive work has been completed on composition of Arctic food and food use, and dietary reference intakes are available.

Objective: To complete the first comprehensive dietary adequacy assessment of three populations of adult Arctic indigenous people.

Setting and subjects: Dietary assessment interviews were conducted with randomly selected indigenous adults during two seasons in 44 representative communities of Yukon First Nations $(n=797)$, Dene/Métis, $(n=1007)$ and Inuit $(n=1525)$.

Methods: Twenty-four-hour recalls were used to derive adjusted distributions of usual nutrient intakes in four age/gender groups for assessment of dietary adequacy for carbohydrate, dietary fibre, protein, $n-3$ fatty acids, $n-6$ fatty acids, calcium, copper, iron, magnesium, manganese, phosphorus, selenium, zinc, vitamin A, riboflavin, folate, vitamin $\mathrm{B}_{6}$, vitamin $\mathrm{C}$, vitamin $\mathrm{D}$ and vitamin $\mathrm{E}$.

Results: Nutrients with high prevalence of adequacy for most age/gender groups in all three cultures were protein, carbohydrate, $n-3$ fatty acids, iron, copper, zinc, manganese, selenium, riboflavin and vitamin $\mathrm{B}_{6}$; some individuals exceeded the upper intake level for iron, zinc, selenium, vitamin A and vitamin D. Estimated average requirement nutrients of concern for adequacy were magnesium, folate, vitamin A, vitamin $\mathrm{C}$ and vitamin $\mathrm{E}$; however, a few age/gender groups were exceptions. Prevalence of inadequacy for AI nutrients which may be undesirably high were fibre, $n-6$ fatty acids and calcium. Vitamin D was more adequate in Inuit women and men than for Yukon First Nations or Dene/Métis.

Conclusions: Unique patterns of dietary adequacy exist among Arctic indigenous peoples. Local wildlife food sources and market food sources should be maximised for their nutrient contributions to Arctic diets.
\end{abstract}

Keywords Indigenous people Arctic Canada

Traditional food

Dietary adequacy
For millennia, indigenous peoples in Arctic Canada have used local, traditional food (TF) systems with knowledge of 100-200 species of wildlife animals and plants existing within cultures, and energy derived primarily from animal and fish meats and fats ${ }^{1-3}$. However, use of this excellent quality food is diminishing due to many social and environmental factors ${ }^{4}$. Today the overall Arctic percentage of daily dietary energy from these food resources averages 22\%, with Yukon First Nations lower at an estimated $17 \%$ and Inuit higher at $28 \%{ }^{5}$. Change from diets entirely of local indigenous foods in most areas of Northern Canada, and indeed in many parts of the world, has taken place within the last 150 years. Nevertheless, this amount of nutrient-dense animal and fish food is still in stark contrast to many global developing areas, where protein is extremely limited, and where inadequacies of many essential nutrients exist ${ }^{6,7}$.

These dietary changes among Northern indigenous peoples are reflected in reduced frequency of use of fewer species than formerly ${ }^{3}$, and by young people consuming less than the older people $e^{4,5,8}$. TF is being displaced in diets by increasing use of purchased ('market') food (MF) of low nutrient density ${ }^{4,5}$ accompanied by decreasing physical activity. These trends result in more obesity in children and adults, and concerns for increasing incidence of chronic disease ${ }^{5,9}$. The same patterns are known in Alaska and the European Arctic ${ }^{10-12}$. These concerns notwithstanding, we have shown that when at 
least one item of TF, usually meat or fish, was included in the day's food in the three major Canadian Arctic cultures, resulting nutrient intakes were significantly and consistently higher than recalls without $\mathrm{TF}^{5}$. This was shown for protein, iron, zinc, copper, magnesium, manganese, potassium, selenium, vitamin $\mathrm{D}$, vitamin $\mathrm{E}$, riboflavin and pyridoxine; for Inuit, vitamin A was also higher with at least one TF item. Days without TF were higher in fat, carbohydrate and sugar. Similar patterns were shown for diets of Dene/Métis children in communities in the Yukon and Northwest Territories (NWT) ${ }^{9,13}$.

Our research on Arctic food systems has necessarily included food composition and interviews on food use and dietary recalls, and has revealed unique nutrient qualities in $\mathrm{TF}^{14-17}$ and dietary patterns ${ }^{5,18}$. With the current dietary reference intakes (DRIs) it is now possible to complete dietary data analysis and report nutrient adequacy of these populations.

Twenty-four-hour recall dietary data were obtained from 44 representative communities over several years in the three major cultural areas of the Canadian Arctic ${ }^{5}$. Leadership within the Governing Board of the Centre for Indigenous Peoples' Nutrition and Environment (CINE) assisted with development of partnerships with communities through the indigenous leadership organisations in the regions: Council of Yukon First Nations, Dene Nation, Métis Nation (NWT) and the Inuit Tapiriit Kanatami. These organisations represent about 65000 of Canada's Aboriginal People in three major Arctic cultures: approximately 7000 in Yukon First Nations, 24000 in Dene/Métis and 34000 Inuit. Our participatory process included joint development of research protocols, reporting research results back to the leadership organisations and communities ${ }^{19}$ using various communication tools (community meetings, radio, posters, etc.), as well as sharing several peer-reviewed publications from this effort $^{3,5,9,13-23}$.

This paper closes the gaps in knowledge of dietary adequacy of these populations of Arctic adults for many nutrients. We report for the first time the extent of variability in intakes and adequacy of many key nutrients and unique patterns for calcium, folate and iron, three nutrients of particular concern in Arctic nutrition.

\section{Subjects and methods}

\section{Sampling and participation}

To briefly review methods of data collection reported earlier ${ }^{5}$, research was accomplished in two seasons in each of 44 communities to get close to annual patterns: that of high TF use (September-November) and low TF use (February-April). Communities representing each culture were selected during initial research meetings which were attended by representatives from all ecological areas. Of the extensive interviews and anthropometric data collected, this report deals exclusively with 24-hour recall data. Studies with each cultural group were separately reviewed by the Human Ethics Committee of McGill University. Science licences were obtained from the responsible Territorial authorities and collective consent was obtained from the Council of Yukon First Nations, Dene Nation, Métis Nation (NWT) and the Inuit Tapiriit Kanatimi. Research agreements were maintained with each community to ensure equitable responsibilities for conduct of the research ${ }^{19}$. The data were collected from 1993 to 1999.

Households in communities were randomly selected in each season (10\% of households or all households in smaller communities up to a maximum of 25), and one adult male and one adult female within households were selected by convenience and interviewed. Participation was voluntary and confidential, and conducted in the traditional language or English by trained community research assistants. Excellent participation rates exceeded 90\% in Dene/Métis and Yukon First Nations and $>75 \%$ for Inuit communities. A trained research coordinator, usually a dietetics or nutrition graduate, was on site frequently to ensure quality control of interviews. Twenty-four-hour recall interviews were conducted in participants' homes with locally available calibrated portion models (cups, bowls, etc.), including a life-scale drawing of bannock, the local bread, and a notebook of TF photos with local names. Interview processes and materials were consistent in the three study regions. Since there was prohibition against use of alcohol in some communities, alcohol intake was recorded when stated, but not probed. Extent of smoking was not asked. Participants were asked if the day's intake was 'usual' or not, including special occasions, to inform discard of inappropriate recalls. Recalls with energy intakes \pm 4 standard deviations from the mean were also discarded. In all, we report data from 3562 adult interviews.

\section{Data entry and databases}

Extensive checking with double entry of a random subset (10\%) was completed, and analyses conducted with SAS, versions 6 and 8 (SAS Institute). Two food composition databases were used for nutrient analysis: (1) a TF database created from our own analysis of Arctic foods ${ }^{15-17,24-29}$; and (2) an MF database derived from Agriculture Handbook $8^{30}$ adjusted for Canadian fortification levels, updated for carotenoid content ${ }^{31}$, adjusted for requirements of the DRIs ${ }^{32}$ and new nutrient data from the US Department of Agriculture ${ }^{33}$. For both databases, there were no missing nutrient values.

\section{Analysis}

Distributions of usual nutrient intakes from adult 24-hour recalls were estimated for Yukon First Nations $(n=797)$, Dene/Métis $(n=1007)$ and Inuit $(n=1525)$ individuals. 
Interviews from pregnant and lactating women were not included in these samples and will be reported separately. The Software for Intake Distribution Estimation (SIDE) software (version 1, 1996, Iowa State University) for SAS version 8.0 (SAS Institute) was used to estimate usual nutrient intake distributions. With a series of transformations and statistical manipulations ${ }^{34-36}$, SIDE uses observed nutrient intakes and repeat observations to estimate distribution of usual nutrient intakes by partitioning the observed inter-individual and intra-individual variance which, in effect, removed intra-individual variance in the data. Variance of measurement error, scaled fourth moment of measurement error and number of individuals with repeat observations in an $11 \%$ subsample of Inuit recalls were used to transform 1-day distributions to distributions of usual intakes for the three cultural groups, thus permitting these intakes to be assessed in an identical manner. Distributions of usual intakes were then used to assess dietary adequacy using the 'cutpoint' method and current DRIs ${ }^{37-44}$. This technique was previously applied to vitamins $\mathrm{A}, \mathrm{D}$ and $\mathrm{E}^{17}$. It was necessary in our research team to estimate total fibre (dietary fibre and functional fibre) and phosphorus separately $^{45}$. For nutrients with an estimated average requirement (EAR), the percentage of the population subgroups with intakes greater than the EAR - under the curve and to the right of the EAR - was used to estimate the portion of the population with adequate intakes (AIs). The cut-point method cannot be applied to iron in young women because menstruating women in the data set result in skewed iron requirement, whereas the cut-point method assumes symmetrical requirement distribution. Therefore, for women in the $\leq 40$-year age group, we used an alternative method by calculating the \% of intakes within specific ranges, multiplied this by the probability of inadequacy of those with intakes within each range, summed across all ranges ${ }^{39,46,47}$ and arithmetically corrected to represent prevalence of adequacy.

For nutrients with an AI as the reference standard, we determined median intakes for the age/gender groups to estimate general adequacy, and report the percentage with intakes greater than or equal to AI. The proportion of the subgroup with intakes at or exceeding the AI gives a general estimation of the population with intakes likely to be adequate.

We computed means and standard errors, medians, 25 th and 75 th percentiles, $\% \geq \mathrm{EAR}, \% \geq \mathrm{AI}$, and the $\% \geq$ upper intake level (UL). Distribution graphs or 25 th and 75th percentile distributions from nutrients in this report are available upon request. Peaks on the graphs indicate modes, which may differ from mean intakes.

For facilitating data management, and to ensure reasonable sample sizes within cells, we collapsed age and gender categories into four groups: women $\leq 40$ years, women $>40$ years, men $\leq 40$ years and men $>40$ years. If the DRI varied over two age groups with similar numbers of data points within a category, we used the mean of the DRI values or a reasonably close DRI value. Nutrients assessed were carbohydrate, fibre, $n-3$ fatty acids, $n-6$ fatty acids, protein, calcium, copper, iron, magnesium, manganese, phosphorus, selenium, zinc, riboflavin, vitamin $\mathrm{A}$, vitamin $\mathrm{B}_{6}$, folate, vitamin $\mathrm{C}$, vitamin D and vitamin E. Calcium, folate and iron were given consideration as nutrients especially salient in Arctic nutrition, and distribution graphs (range of intake and probability density) and additional discussion are presented. Distribution graphs and partial data from vitamins $\mathrm{A}, \mathrm{D}$ and $\mathrm{E}$ are presented elsewhere. ${ }^{17}$ To reduce confusion on reporting adequacy in tables presented here, we show medians, the EAR or $\mathrm{AI}$, and the $\% \geq \mathrm{EAR}$ or $\mathrm{AI}$.

\section{Nutrient supplements}

Supplement intake information was requested in all 24-hour recalls: the interviewee was asked if she/he consumed any nutrient supplement and the corresponding brand name(s), if known. Less than 5\% of non-pregnant, non-lactating adults reported using a supplement. Since these approximately 80 recalls recorded 23 different types/brands of supplements, it was agreed to disregard nutrient intakes from supplements in the data set for normal adults.

\section{Results}

\section{Estimated usual nutrient intakes and percentiles of dietary adequacy of adults}

Estimated usual nutrient intakes as medians and \% exceeding the EAR or AI are presented in Tables 1-3. Data are presented first for Yukon First Nations (Table 1), followed by Dene/Métis (Table 2) and Inuit (Table 3). Macronutrients (carbohydrate, fibre, protein, $n-3$ and $n-6$ fatty acids), minerals (Ca, Cu, Fe, Mg, Mn, P, $\mathrm{Se}, \mathrm{Zn}$ ) and vitamins (vitamin $\mathrm{A}$, riboflavin, $\mathrm{B}_{6}$, folate, $\mathrm{C}$, $\mathrm{D}, \mathrm{E})$ are reported for women $\leq 40$ and $>40$ years, and men $\leq 40$ and $>40$ years. Results from the three cultures are given by nutrient. For ease in interpreting each table, EAR nutrients are presented first, followed by AI nutrients. Results with discussion of calcium, folate and iron are given separately.

A few individuals in culture, age and gender groups exceeded the ULs for selenium, zinc, iron, vitamin A and vitamin D. Percentages of groups above the ULs are noted in the following discussion of each nutrient.

\section{EAR nutrients}

As expected, carbohydrate and protein as EAR nutrients were adequate, with 99-100\% exceeding the EAR. Of the minerals assessed with EARs, there was high prevalence of adequacy for copper, with $>98 \%$ exceeding the EAR in age and gender categories. Similar high percentages of 
Table 1 Estimated usual nutrient intakes of Yukon* participants and DRI percentage

\begin{tabular}{|c|c|c|c|c|c|c|c|c|c|}
\hline \multirow[b]{2}{*}{ Age (years) } & \multicolumn{9}{|c|}{ EAR nutrients } \\
\hline & Median & EAR & $\% \geq \mathrm{EAR}$ & Median & EAR & $\% \geq E A R$ & Median & EAR & $\% \geq \mathrm{EAR}$ \\
\hline & \multicolumn{3}{|c|}{ Carbohydrate (g) } & \multicolumn{3}{|c|}{ Protein (g) } & \multicolumn{3}{|c|}{ Copper $(\mu \mathrm{g})$} \\
\hline $\begin{array}{l}F \leq 40 \\
F>40 \\
M \leq 40 \\
M>40\end{array}$ & $\begin{array}{l}184 \\
191 \\
208 \\
184\end{array}$ & $\begin{array}{l}100 \\
100 \\
100 \\
100\end{array}$ & $\begin{array}{c}100 \\
100 \\
100 \\
94.1\end{array}$ & $\begin{array}{c}98.0 \\
100 \\
145 \\
150\end{array}$ & $\begin{array}{l}38 t \\
38 t \\
46 t \\
46 t\end{array}$ & $\begin{array}{l}100 \\
100 \\
100 \\
100\end{array}$ & $\begin{array}{l}1175 \\
1406 \\
1808 \\
1406\end{array}$ & $\begin{array}{l}700 \\
700 \\
700 \\
700\end{array}$ & $\begin{array}{c}99.6 \\
100 \\
100 \\
100\end{array}$ \\
\hline$M>40$ & \multicolumn{3}{|c|}{ Iron (mg) } & \multicolumn{3}{|c|}{ Magnesium (mg) } & \multicolumn{3}{|c|}{ Phosphorus (mg) } \\
\hline $\begin{array}{l}F \leq 40 \\
F>40 \\
M \leq 40 \\
M>40\end{array}$ & $\begin{array}{l}14.4 \\
16.6 \\
20.0 \\
19.9\end{array}$ & $\begin{array}{l}8.1 \\
8.0 \S \\
6.0 \\
6.0\end{array}$ & $\begin{array}{l}95.6 \ddagger \\
100 \\
100 \\
100\end{array}$ & $\begin{array}{l}244 \\
247 \\
287 \\
279\end{array}$ & $\begin{array}{c}335 \S \\
350 \\
350 \S \\
350\end{array}$ & $\begin{array}{r}6.0 \\
4.0 \\
1.0 \\
11.0\end{array}$ & $\begin{array}{l}1075 \\
1204 \\
1445 \\
1362\end{array}$ & $\begin{array}{l}580 \\
580 \\
580 \\
580\end{array}$ & $\begin{array}{l}92.7 \\
97.6 \\
97.3 \\
97.5\end{array}$ \\
\hline$M>40$ & \multicolumn{3}{|c|}{ Selenium $(\mu \mathrm{g})$} & \multicolumn{3}{|c|}{ Zinc (mg) } & \multicolumn{3}{|c|}{ Vitamin A ( $\mu$ g RAE) } \\
\hline $\begin{array}{l}F \leq 40 \\
F>40 \\
M \leq 40 \\
M>40\end{array}$ & $\begin{array}{l}109 \\
104 \\
143 \\
157\end{array}$ & $\begin{array}{l}45 \\
45 \\
45 \\
45\end{array}$ & $\begin{array}{c}100 \\
99.2 \\
100 \\
100\end{array}$ & $\begin{array}{l}14.0 \\
16.1 \\
24.0 \\
23.6\end{array}$ & $\begin{array}{l}6.8 \\
6.8 \\
9.4 \\
9.4\end{array}$ & $\begin{array}{l}99.5 \\
99.7 \\
99.4 \\
98.9\end{array}$ & $\begin{array}{r}683 \\
1220 \\
964 \\
972\end{array}$ & $\begin{array}{l}500 \\
500 \\
625 \\
625\end{array}$ & $\begin{array}{c}45.0 \\
85.0 \\
100 \\
59.0\end{array}$ \\
\hline$M>40$ & \multicolumn{3}{|c|}{ Riboflavin (mg) } & \multicolumn{3}{|c|}{ Folate ( $\mu$ g DFE) } & \multicolumn{3}{|c|}{ Vitamin $\mathrm{B}_{6}(\mathrm{mg})$} \\
\hline $\begin{array}{l}F \leq 40 \\
F>40 \\
M \leq 40 \\
M>40\end{array}$ & $\begin{array}{l}1.4 \\
1.3 \\
1.8 \\
1.9\end{array}$ & $\begin{array}{l}0.9 \\
0.9 \\
1.1 \\
1.1\end{array}$ & $\begin{array}{l}99.0 \\
94.0 \\
98.0 \\
95.0\end{array}$ & $\begin{array}{l}267 \\
294 \\
322 \\
319\end{array}$ & $\begin{array}{l}320 \\
320 \\
320 \\
320\end{array}$ & $\begin{array}{r}2.0 \\
38.0 \\
54.0 \\
49.0\end{array}$ & $\begin{array}{l}2.0 \\
2.2 \\
2.9 \\
3.2\end{array}$ & $\begin{array}{l}1.1 \\
1.3 \S \\
1.1 \\
1.4 \S\end{array}$ & $\begin{array}{l}100 \\
100 \\
100 \\
100\end{array}$ \\
\hline$M>40$ & \multicolumn{3}{|c|}{ Vitamin C (mg) } & \multicolumn{3}{|c|}{ Vitamin E (mg) } & & & \\
\hline $\begin{array}{l}F \leq 40 \\
F>40 \\
M \leq 40 \\
M>40\end{array}$ & $\begin{array}{l}69.2 \\
61.2 \\
75.3 \\
56.0\end{array}$ & $\begin{array}{l}60 \\
60 \\
75 \\
75\end{array}$ & $\begin{array}{r}69.0 \\
52.0 \\
51.0 \\
0.0\end{array}$ & $\begin{array}{l}3.0 \\
3.2 \\
3.3 \\
3.2\end{array}$ & $\begin{array}{l}12 \\
12 \\
12 \\
12\end{array}$ & $\begin{array}{l}0.0 \\
0.0 \\
0.0 \\
0.0\end{array}$ & & & \\
\hline \multirow{3}{*}{$M>40$} & & & & \multicolumn{3}{|c|}{ Al nutrients } & & & \\
\hline & Median & $\mathrm{Al}$ & $\% \geq \mathrm{Al}$ & Median & $\mathrm{Al}$ & $\% \geq \mathrm{Al}$ & Median & $\mathrm{Al}$ & $\% \geq \mathrm{Al}$ \\
\hline & \multicolumn{3}{|c|}{ Dietary fibre $(\mathrm{g})$} & \multicolumn{3}{|c|}{$n-3$ fatty acids $(\mathrm{g})$} & \multicolumn{3}{|c|}{$n-6$ fatty acids $(\mathrm{g}) \|$} \\
\hline $\begin{array}{l}F \leq 40 \\
F>40 \\
M \leq 40 \\
M>40\end{array}$ & $\begin{array}{r}9.6 \\
9.1 \\
11.4 \\
10.2\end{array}$ & $\begin{array}{l}23 \S \\
23 \S \\
34 \S \\
34 \S\end{array}$ & $\begin{array}{l}0.0 \\
0.6 \\
0.9 \\
0.6\end{array}$ & $\begin{array}{l}1.3 \\
1.3 \\
1.6 \\
2.0\end{array}$ & $\begin{array}{l}1.1 \\
1.1 \\
1.6 \\
1.6\end{array}$ & $\begin{array}{l}85.0 \\
85.0 \\
40.0 \\
87.0\end{array}$ & $\begin{array}{r}8.1 \\
8.0 \\
12.9 \\
10.0\end{array}$ & $\begin{array}{l}11.5 \$ \\
11.5 \$ \\
15.5 \$ \\
15.5 \$\end{array}$ & $\begin{array}{r}6.0 \\
14.0 \\
0.0 \\
2.0\end{array}$ \\
\hline$M>40$ & \multicolumn{3}{|c|}{ Calcium (mg) } & \multicolumn{3}{|c|}{ Manganese (mg) } & \multicolumn{3}{|c|}{ Vitamin D $(\mu \mathrm{g})$} \\
\hline $\begin{array}{l}F \leq 40 \\
F>40 \\
M \leq 40 \\
M>40\end{array}$ & $\begin{array}{l}535 \\
481 \\
509 \\
502\end{array}$ & $\begin{array}{r}1000 \\
1200 \S \\
1000 \\
1200 \S\end{array}$ & $\begin{array}{l}1.0 \\
0.0 \\
0.0 \\
3.0\end{array}$ & $\begin{array}{l}2.7 \\
4.1 \\
2.6 \\
3.4\end{array}$ & $\begin{array}{l}1.8 \\
1.8 \\
2.3 \\
2.3\end{array}$ & $\begin{array}{c}88.1 \\
100 \\
99.2 \\
94.3\end{array}$ & $\begin{array}{l}4.6 \\
4.9 \\
3.0 \\
5.0\end{array}$ & $\begin{array}{r}5 \\
10 \S \\
5 \\
10 \S\end{array}$ & $\begin{array}{r}30.0 \\
0.0 \\
0.0 \\
12.0\end{array}$ \\
\hline
\end{tabular}

adequacy are evident for phosphorus, selenium and zinc. Some Inuit individuals exceeded the UL for selenium ( $8.5 \%$ of older women and $6 \%$ of older men); a few individuals exceeded the UL for zinc $(1.6 \%$ of older women, $2.5 \%$ of younger men and $2.4 \%$ of older men). Similarly, $5.5 \%$ of younger men and $8.9 \%$ of older men in Yukon First Nations exceeded the zinc UL (data not shown). However, with respect to magnesium, almost all fell below the EAR, with 0-16\% prevalence of adequacy for Yukon First Nations and Dene; Inuit fared somewhat better with 5-22\% prevalence of adequacy.

The EAR vitamins assessed showed interesting patterns. As previously noted ${ }^{17,22}$, vitamin A nutrition was diverse by age and gender. In all three cultures, younger 
Table 2 Estimated usual nutrient intakes of Dene/Métis* participants and DRI percentage

\begin{tabular}{|c|c|c|c|c|c|c|c|c|c|}
\hline \multirow[b]{2}{*}{ Age (years) } & \multicolumn{9}{|c|}{ EAR nutrients } \\
\hline & Median & EAR & $\% \geq \mathrm{EAR}$ & Median & EAR & $\% \geq E A R$ & Median & EAR & $\% \geq \mathrm{EAR}$ \\
\hline & \multicolumn{3}{|c|}{ Carbohydrate (g) } & \multicolumn{3}{|c|}{ Protein $(\mathrm{g})$} & \multicolumn{3}{|c|}{ Copper $(\mu \mathrm{g})$} \\
\hline $\begin{array}{l}F \leq 40 \\
F>40 \\
M \leq 40 \\
M>40\end{array}$ & $\begin{array}{l}224 \\
177 \\
251 \\
189\end{array}$ & $\begin{array}{l}100 \\
100 \\
100 \\
100\end{array}$ & $\begin{array}{c}100 \\
98.6 \\
100 \\
100\end{array}$ & $\begin{array}{l}111 \\
126 \\
126 \\
170\end{array}$ & $\begin{array}{l}38 t \\
38+ \\
46 t \\
46+\end{array}$ & $\begin{array}{l}100 \\
100 \\
100 \\
100\end{array}$ & $\begin{array}{l}1554 \\
1918 \\
1929 \\
1575\end{array}$ & $\begin{array}{l}700 \\
700 \\
700 \\
700\end{array}$ & $\begin{array}{l}100 \\
100 \\
100 \\
100\end{array}$ \\
\hline$M>40$ & \multicolumn{3}{|c|}{ Iron (mg) } & \multicolumn{3}{|c|}{ Magnesium (mg) } & \multicolumn{3}{|c|}{ Phosphorus (mg) } \\
\hline $\begin{array}{l}F \leq 40 \\
F>40 \\
M \leq 40 \\
M>40\end{array}$ & $\begin{array}{l}16.0 \\
32.3 \\
25.7 \\
23.3\end{array}$ & $\begin{array}{l}8.1 \\
8.0 \S \\
6.0 \\
6.0\end{array}$ & $\begin{array}{c}94.7 \ddagger \\
100 \\
100 \\
100\end{array}$ & $\begin{array}{l}256 \\
274 \\
318 \\
285\end{array}$ & $\begin{array}{r}335 \S \\
350 \\
350 \S \\
350\end{array}$ & $\begin{array}{r}9.0 \\
0.0 \\
16.0 \\
0.0\end{array}$ & $\begin{array}{l}1203 \\
1481 \\
1538 \\
1637\end{array}$ & $\begin{array}{l}580 \\
580 \\
580 \\
580\end{array}$ & $\begin{array}{l}95.3 \\
99.6 \\
99.2 \\
99.2\end{array}$ \\
\hline & \multicolumn{3}{|c|}{ Selenium $(\mu \mathrm{g})$} & \multicolumn{3}{|c|}{ Zinc (mg) } & \multicolumn{3}{|c|}{ Vitamin A ( $\mu$ g RAE) } \\
\hline $\begin{array}{l}F \leq 40 \\
F>40 \\
M \leq 40 \\
M>40\end{array}$ & $\begin{array}{l}113 \\
130 \\
156 \\
145\end{array}$ & $\begin{array}{l}45 \\
45 \\
45 \\
45\end{array}$ & $\begin{array}{l}100 \\
100 \\
100 \\
100\end{array}$ & $\begin{array}{l}16.4 \\
24.0 \\
25.0 \\
21.4\end{array}$ & $\begin{array}{l}6.8 \\
6.8 \\
9.4 \\
9.4\end{array}$ & $\begin{array}{c}99.7 \\
100 \\
100 \\
99.7\end{array}$ & $\begin{array}{l}420 \\
397 \\
527 \\
404\end{array}$ & $\begin{array}{l}500 \\
500 \\
625 \\
625\end{array}$ & $\begin{array}{r}0.0 \\
19.0 \\
0.0 \\
4.0\end{array}$ \\
\hline$M>40$ & \multicolumn{3}{|c|}{ Riboflavin (mg) } & \multicolumn{3}{|c|}{ Folate ( $\mu$ g DFE) } & \multicolumn{3}{|c|}{ Vitamin $B_{6}(\mathrm{mg})$} \\
\hline $\begin{array}{l}F \leq 40 \\
F>40 \\
M \leq 40 \\
M>40\end{array}$ & $\begin{array}{l}1.6 \\
2.0 \\
1.8 \\
2.1\end{array}$ & $\begin{array}{l}0.9 \\
0.9 \\
1.1 \\
1.1\end{array}$ & $\begin{array}{l}100 \\
100 \\
100 \\
100\end{array}$ & $\begin{array}{l}309 \\
254 \\
369 \\
320\end{array}$ & $\begin{array}{l}320 \\
320 \\
320 \\
320\end{array}$ & $\begin{array}{r}43.5 \\
0.6 \\
91.1 \\
50.0\end{array}$ & $\begin{array}{l}2.4 \\
3.6 \\
2.6 \\
3.6\end{array}$ & $\begin{array}{l}1.1 \\
1.3 \S \\
1.1 \\
1.4 \S\end{array}$ & $\begin{array}{c}99.0 \\
100 \\
100 \\
100\end{array}$ \\
\hline$M>40$ & \multicolumn{3}{|c|}{ Vitamin C (mg) } & \multicolumn{3}{|c|}{ Vitamin E (mg) } & & & \\
\hline $\begin{array}{l}F \leq 40 \\
F>40 \\
M \leq 40 \\
M>40\end{array}$ & $\begin{array}{l}72.0 \\
49.0 \\
91.0 \\
51.0\end{array}$ & $\begin{array}{l}60 \\
60 \\
75 \\
75\end{array}$ & $\begin{array}{l}73.0 \\
30.0 \\
96.0 \\
15.0\end{array}$ & $\begin{array}{l}4.6 \\
6.8 \\
6.5 \\
6.2\end{array}$ & $\begin{array}{l}12 \\
12 \\
12 \\
12\end{array}$ & $\begin{array}{l}0.0 \\
0.0 \\
0.0 \\
0.0\end{array}$ & & & \\
\hline \multirow{3}{*}{$M>40$} & & & & \multicolumn{3}{|c|}{ Al nutrients } & & & \\
\hline & Median & $\mathrm{Al}$ & $\% \geq \mathrm{Al}$ & Median & $\mathrm{Al}$ & $\% \geq \mathrm{Al}$ & Median & $\mathrm{Al}$ & $\% \geq \mathrm{Al}$ \\
\hline & \multicolumn{3}{|c|}{ Dietary fibre (g) } & \multicolumn{3}{|c|}{$n-3$ fatty acids $(\mathrm{g})$} & \multicolumn{3}{|c|}{$n-6$ fatty acids $(\mathrm{g}) \|$} \\
\hline $\begin{array}{l}F \leq 40 \\
F>40 \\
M \leq 40 \\
M>40\end{array}$ & $\begin{array}{l}8.3 \\
7.3 \\
8.7 \\
7.7\end{array}$ & $\begin{array}{l}23 \S \\
23 \S \\
34 \S \\
34 \S\end{array}$ & $\begin{array}{l}0.0 \\
0.0 \\
0.0 \\
0.0\end{array}$ & $\begin{array}{l}1.6 \\
1.6 \\
1.8 \\
2.0\end{array}$ & $\begin{array}{l}1.1 \\
1.1 \\
1.6 \\
1.6\end{array}$ & $\begin{array}{r}98.0 \\
86.0 \\
88.0 \\
100\end{array}$ & $\begin{array}{l}10.3 \\
10.9 \\
10.7 \\
14.3\end{array}$ & $\begin{array}{l}11.5 \$ \\
11.5 \$ \\
15.5 \S \\
15.5 \S\end{array}$ & $\begin{array}{r}23.0 \\
39.0 \\
0.0 \\
29.0\end{array}$ \\
\hline$M>40$ & \multicolumn{3}{|c|}{ Calcium (mg) } & \multicolumn{3}{|c|}{ Manganese (mg) } & \multicolumn{3}{|c|}{ Vitamin D $(\mu \mathrm{g})$} \\
\hline $\begin{array}{l}F \leq 40 \\
F>40 \\
M \leq 40 \\
M>40\end{array}$ & $\begin{array}{l}540 \\
520 \\
750 \\
546\end{array}$ & $\begin{array}{r}1000 \\
1200 \S \\
1000 \\
1200 \S\end{array}$ & $\begin{array}{l}1.3 \\
0.0 \\
0.0 \\
3.5\end{array}$ & $\begin{array}{l}2.9 \\
4.2 \\
3.3 \\
3.5\end{array}$ & $\begin{array}{l}1.8 \\
1.8 \\
2.3 \\
2.3\end{array}$ & $\begin{array}{c}100 \\
100 \\
95.5 \\
100\end{array}$ & $\begin{array}{l}3.0 \\
5.2 \\
6.2 \\
9.4\end{array}$ & $\begin{array}{r}5 \\
10 \S \\
5 \\
10 \S\end{array}$ & $\begin{array}{r}5.0 \\
0.0 \\
75.0 \\
41.0\end{array}$ \\
\hline $\begin{array}{l}\text { DRI - dietary } \\
\text { equivalents. } \\
{ }^{\circ} \mathrm{F} \leq 40: n=2 \\
+ \text { Calculated as } \\
\text { † Calculated us } \\
\text { § Assumed DR } \\
\text { T For } \alpha \text {-linolen } \\
\text { |l For linoleic a }\end{array}$ & $\begin{array}{l}\text { ence intak } \\
>40: n= \\
g^{-1} \times 5 \\
\text { anges. } \\
\text { ee because } \\
\text { d only. } \\
\text { ly. }\end{array}$ & $\begin{array}{l}\text { AR - estir } \\
M \leq 40: n \\
\text { for } F \text {, and } \\
\text { ge cut-off }\end{array}$ & $\begin{array}{l}\text { average re } \\
\mathrm{M}>40: n=\mathrm{gg}^{-1} \times 7\end{array}$ & $\begin{array}{l}\text { ment; Al } \\
\text { for M. }\end{array}$ & quate & RAE - retir & & & etary folate \\
\hline
\end{tabular}

women had lower prevalence of adequacy (0-53\% $\geq$ EAR). Older Yukon and Inuit women and men fared somewhat better (59-93\% adequate) and 3\% of older Inuit women and $7 \%$ of older Inuit men exceeded the $\mathrm{UL}$, as reported earlier ${ }^{17}$. Younger men were either all inadequate ( $0 \%$ above the EAR - Dene/Métis), medium
(56\% - Inuit) or completely adequate (100\% - Yukon). Of the three cultures, Dene/Métis had the poorest vitamin A intakes for all age/gender groups (0-19\% adequate).

There was high prevalence of adequacy of riboflavin in Yukon and Dene/Métis diets (>90\% adequate), but Inuit had $40-57 \%$ adequacy in age/gender categories. Most 
Table 3 Estimated usual nutrient intakes of Inuit* participants and DRI percentage

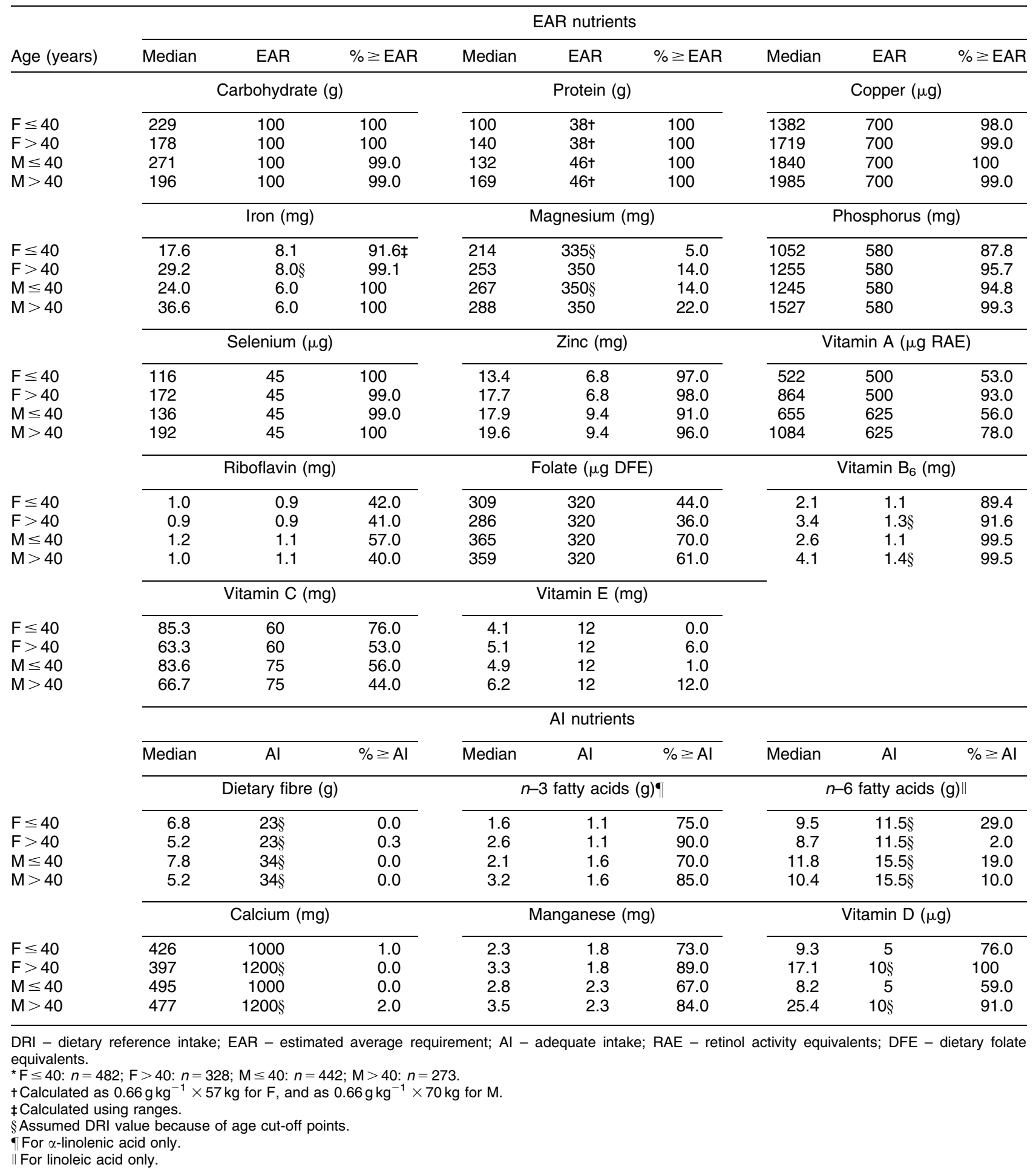

people in all cultures met or exceeded the vitamin $\mathrm{B}_{6}$ EAR (>89\% adequate). For vitamin C, diverse patterns existed with 0-99\% adequate; in each culture the least \% adequacy was for older men; younger Dene men had the greatest $\%$ adequacy $(96 \% \geq \mathrm{EAR})$. Since smoking is known to be extensive in the Arctic, these estimates of vitamin $\mathrm{C}$ adequacy may be inflated. Vitamin $\mathrm{E}$ was a consistent concern across all cultures and age/gender categories, with only $0-12 \%$ prevalence of adequacy.

\section{AI nutrients}

Fibre was also an outstanding concern in all age/gender categories with median intakes far below the AI and $<1 \%$ exceeding the AI; therefore, the prevalence of inadequacy 
may be undesirably high. Median intakes of the $n-3$ fatty acids consistently exceeded the AI and $40-100 \%$ of age/gender groups exceeded the AI, indicating general adequacy. However, medians for the $n-6$ fatty acids in all age/gender categories for the three cultures were below the $\mathrm{AI}$, with $0-39 \%$ exceeding the $\mathrm{AI}$, thus indicating prevalence of inadequacy likely being undesirably high. Manganese, as an AI nutrient, had likely high prevalence of adequacy; median intakes consistently exceeded the AI and $67-100 \%$ of participant intakes exceeded the AI.

Vitamin D nutrition was better for Inuit than for Yukon First Nations or Dene/Métis. In Yukon First Nations and Dene/Métis, age/gender category medians were below the AI, with the exception of young Dene/Métis men (median at $6.2 \mu \mathrm{g}, 75 \%$ exceeding the AI). Other men and all women in the Yukon and Dene/Métis regions had $0-41 \%$ who exceeded the AI, indicating mixed patterns of adequacy. In contrast, median intakes in the Inuit age/ gender groups all exceeded the AI, with $59-100 \%$ above the AI. There is therefore little concern for vitamin D inadequacy among Inuit adults; in fact, $17 \%$ of older Inuit men exceeded the vitamin D UL ${ }^{17}$, the consequences of which are not known.

With respect to energy intakes, we noted earlier ${ }^{5}$ that in these same age categories, obesity varied from 7 to $38 \%$ among women and from 5 to $21 \%$ among men, exceeding the all-Canadian averages. An earlier report showed that total fat as $\%$ of energy was significantly higher $(37-40 \%$ of energy vs. 30-32\% of energy) for all cultural groups when TF (meat, fish) was not included in the diet, and fats and protein were provided by purchased foods, particularly meats. Similar patterns were shown with non-TF diets containing significantly more saturated fat and sucrose than TF-containing diets ${ }^{5}$. We, therefore, maintain that energy intakes are high and exceed energy expenditures ${ }^{43}$.

\section{Calcium}

Because median intakes were consistently below the AI (481-750 $\mathrm{mg} \mathrm{day}^{-1}$ ), and less than $4 \%$ of all age/gender groups in the three cultural areas exceeded the AI, there is concern for undesirably high prevalence of inadequacy. Figure 1 clearly demonstrates these low intakes with probability distributions in the four age/gender groups of each culture. Inuit distributions of intake are broad and most consistent across age/gender groups of the three cultures, indicating similar food patterns. Vitamin D is a nutrient metabolically linked to calcium, and important in many respects; however, when considering bone health and the DRIs, calcium appears more limiting than vitamin $\mathrm{D}$ in diets of all three cultural groups.

\section{Folate}

As an EAR nutrient, folate intakes were lowest for all women $(0.6-44 \%$ prevalence of adequacy), but better for men. Young Dene/Métis and Inuit men had highest folate
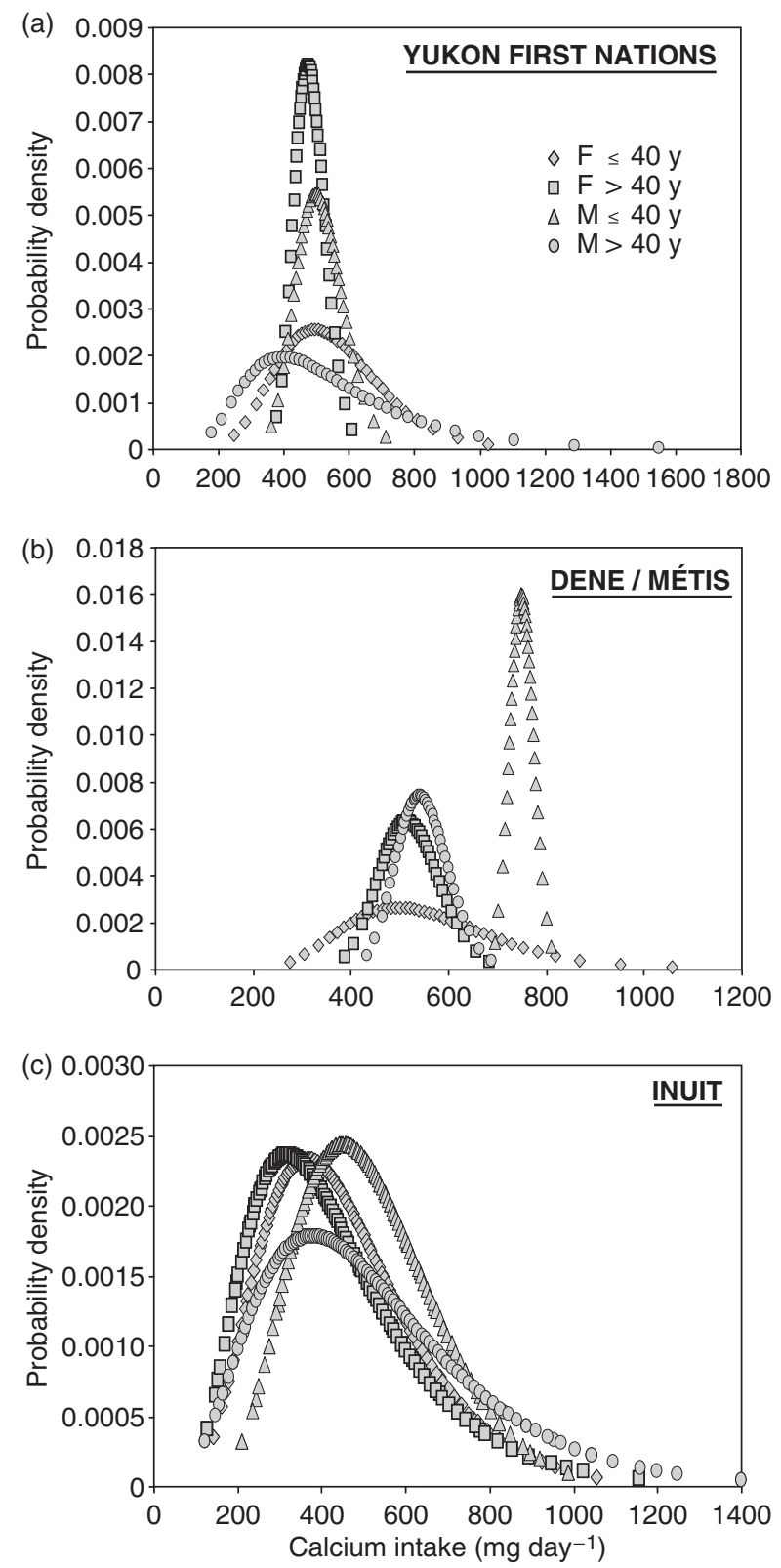

Fig. 1 Probability distributions for calcium intakes by Yukon (a), Dene/Métis (b) and Inuit participants (c). The adequate intake is $1000 \mathrm{mg} \mathrm{day}^{-1}$ for individuals $\leq 40$ years, and is assumed at $1200 \mathrm{mg} \mathrm{day}^{-1}$ for individuals $>40$ years. The upper intake level is $2500 \mathrm{mg} \mathrm{day}^{-1}$ for all. See Tables $1-3$ for sample sizes

intakes with 70-91\% prevalence of adequacy. The probability distributions of folate intakes as $\mu \mathrm{g}$ dietary folate equivalents (DFE) day ${ }^{-1}$ are shown in Fig. 2 . The narrow distributions of folate intakes of younger Yukon women and men and older Dene women are of interest, likely reflecting similar food sources and quantities consumed. In the absence of consistent folate supplement use, adequacy is a concern for this nutrient for young women who may become pregnant. 

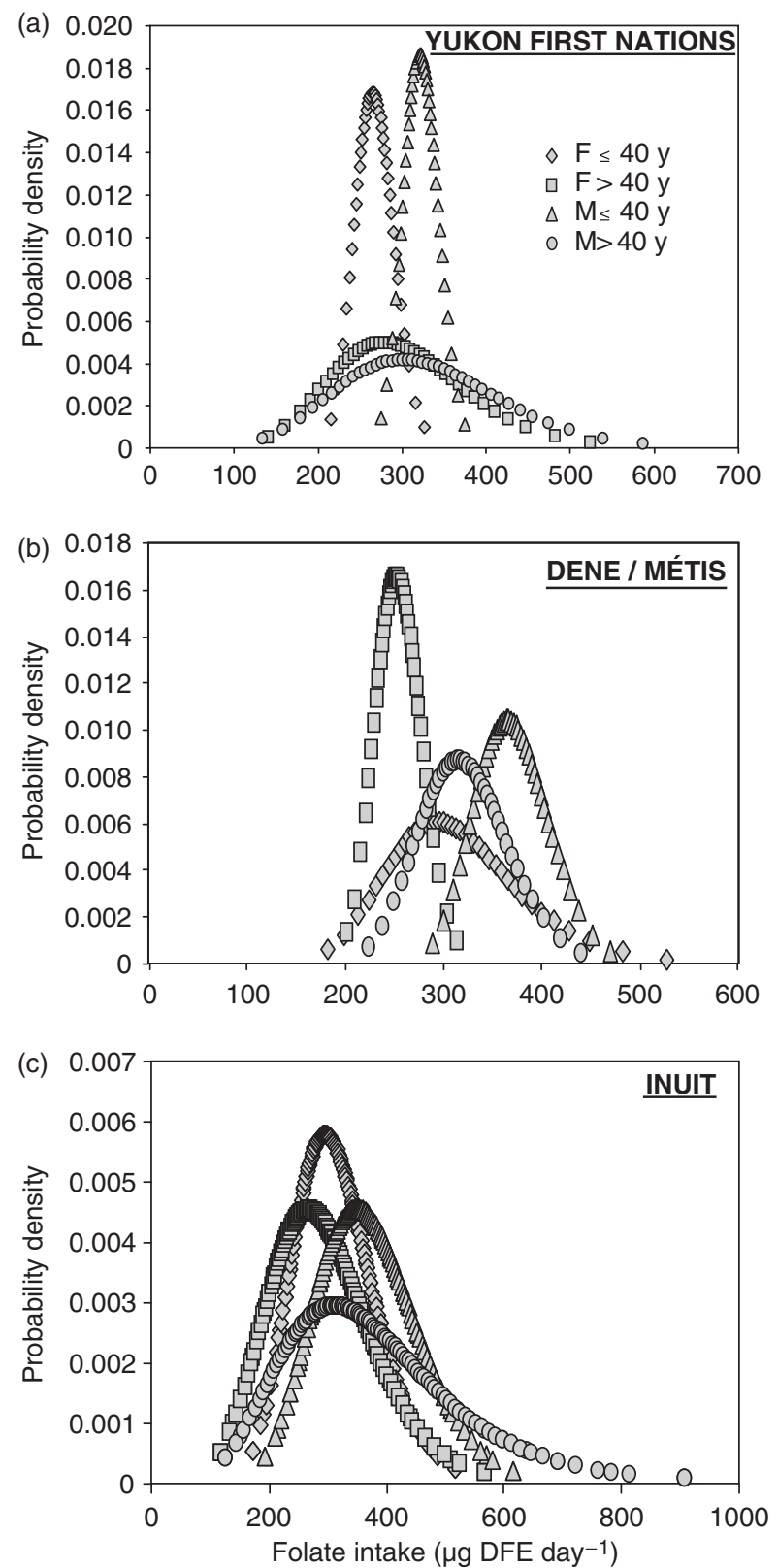

Fig. 2 Probability distributions for folate intakes by Yukon (a), Dene/Métis (b) and Inuit participants (c). The estimated average requirement is $320 \mu \mathrm{g}$ dietary folate equivalents (DFE) per day for all. The upper intake applies only to synthetic forms. See Tables 1-3 for sample sizes

Iron

Figure 3 gives the probability distributions of iron intakes in $\mathrm{mgday}^{-1}$. Immediately apparent is the consistent prevalence of adequacy, with high iron intakes, undoubtedly due to high meat and fish intakes. Very few fell below the EAR for iron. Using the alternative method for calculating intakes for young women, the results for prevalence of adequacy are 91-100\%. Of concern for iron nutrition was exceeding the UL $\left(>45 \mathrm{mgday}^{-1}\right)$ by many Inuit women (23\%) and men (30\%) in older age
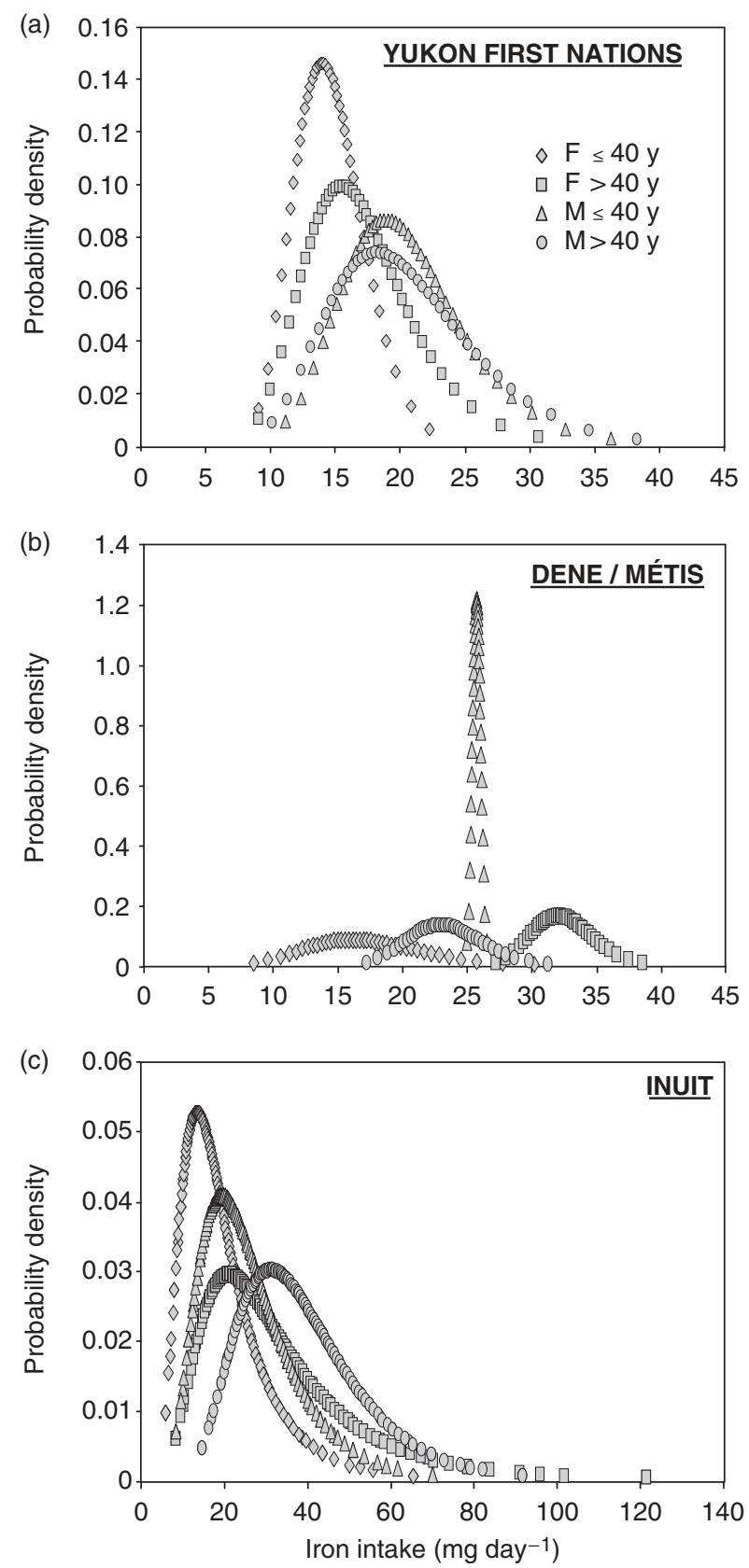

Fig. 3 Probability distributions for iron intakes by Yukon (a), Dene/Métis (b) and Inuit participants (c). The estimated average requirement is $8.1 \mathrm{mg} \mathrm{day}^{-1}$ for females $\leq 40$ years, is assumed at $8.0 \mathrm{mg} \mathrm{day}^{-1}$ for females $>40$ years, and is $6.0 \mathrm{mg} \mathrm{day}^{-1}$ for all males. The upper intake is $45 \mathrm{mg} \mathrm{day}^{-1}$ for all. See Tables 1-3 for sample sizes

categories. Four per cent of young Inuit women and 8\% of young Inuit men also exceeded the iron UL.

\section{Discussion}

With the amount of TF consumed by these three cultures at approximately $22 \%(17-28 \%$ averaged by culture) of 
total dietary energy, it is important to reflect upon the contributions of both TF and MF to these nutrient patterns. The extent of combined TF and MF meat and fish being consumed was close to a cultural average of $40 \%$ of dietary energy ${ }^{48}$. This extent of meat and fish consumption obviously determined extent of adequacy for protein, iron, zinc, manganese, copper, phosphorus, selenium, riboflavin and vitamin $\mathrm{B}_{6}$. Other nutrients were also affected by this dietary pattern. For example, the $n-3$ fatty acids are abundant in TF, particularly fish and sea mammal fats. Low intakes of $n-6$ fatty acids as well as vitamin E reflect on MF choices containing little visible oils, nuts or legumes.

The extent of adequacy of vitamin A and vitamin D also mirrors animal and fish fat in $\mathrm{TF}^{17,28}$. Yukon First Nations and Inuit had higher median intakes than Dene/Métis for vitamin A. Inuit median intakes consistently exceeded the $\mathrm{AI}$ (with \% exceeding the AI also being high) reflecting extensive use of fish and sea mammal fats. Interestingly, older Inuit men consuming the most TF, including organ meats ${ }^{5}$, were the only age/gender group of the three cultural areas with some individuals (12\%) who demonstrated adequacy for vitamin E; this same group also had individuals who exceeded the UL (17\%) for vitamin D.

Concerns for adequacy of calcium, magnesium and vitamin D coincided with very limited consumption of dairy products ${ }^{48}$. However, this does not seem to impact importantly on adequacy for riboflavin, likely due to enrichment of grain products with riboflavin. Although there was little reported intake of dairy products in the Arctic $^{48}$, public education attempts to increase use of dairy products have not been effective strategies to date, because these foods are not commonly purchased due to cost, poor quality due to shelf life and exclusion from preferred menu patterns.

MF is also fortified with vitamin C (beverage powders) and folate (beverage powders, flour and flour products). Reconstituted beverage powder drinks are consumed a great deal, especially in the NWT. With fortification of flour with folate, the major food source was the commonly consumed white wheat flour bread, bannock ${ }^{21}$ (90 $\mu \mathrm{g}$ $\mathrm{DFE} / 100 \mathrm{~g})$, or white bread $(120 \mu \mathrm{g}$ DFE/100 g). Mean daily food portions of the grain food group in all three cultures varied from 113 to $249 \mathrm{~g} \mathrm{day}^{-1}$, with men consuming more than women (not shown). Inuit consumed less total bannock/grains and folate than did Dene/Métis or Yukon individuals, but they consumed more organ meats, also good sources of folate (personal communication). As noted earlier, vegetable and fruit consumption is a minor part of dietary energy in the $\operatorname{Arctic}^{8,14}$, and likely contributes minimal dietary folate. As well, limited use of whole grains and vegetables and fruits contributes to the overall concern for adequacy of dietary fibre.

Iron is universally adequate in Arctic adult diets due to large amounts of bioavailable meat and fish consumption as well as fortified grain products. In considering iron nutrition, the possibility of anaemia in Arctic populations resulting from infection with Helicobacter pylori cannot be ruled out. H. pylori infection and anaemia has been documented in Alaska adults and children and in Northern Quebec pregnant women and infants ${ }^{49-52}$. If H. pylori infection contributes to anaemia among Arctic women, consideration must be taken to ensure highly bioavailable iron intakes from meats and supplements along with need for infection control. Research and reconsideration of the iron EAR and UL, as well as other nutrients affected by impaired gastrointestinal absorption and stool blood loss are needed, if traditional lifestyle is maintained without infection control. Further, the extent of anaemia in Arctic populations, particularly women and children, needs to be carefully assessed along with occurrence of $H$. pylori infection during routine physical assessments. Research is urgently needed into these key ecologic and public health issues.

There are some limitations of this work. Firstly, it was impossible to have a complete set of nutrients in the food composition database of Arctic food which were analysed in our laboratory and with consulting laboratories. This therefore precluded including a complete nutrient picture (including several vitamins) even though data for additional nutrients were available from the MF database. Secondly, several years have passed since the first dietary data were collected. Evolution of food composition data and the DRIs have required use of recent food composition information for dietary data collected earlier. However, from our recent community work, we feel the dietary survey data have remained valid and worth reporting. Fourthly, second day recalls for Yukon and Dene/Métis were not taken since this research was conducted before knowledge evolved for this requirement ${ }^{38}$. Using the Inuit 11\% subsample for calculating the ratio of between-person variation over observed variation was a reasonable compromise, since all three Arctic cultures shared use of similar MF for $>70-80 \%$ of dietary energy. Finally, we recognise that collapsing some age categories for these evaluations and using approximate DRIs combining those of two age groups is not completely accurate. However, we feel it presents a minor error in comparison to prevalence estimations.

\section{Recommendations}

Many nutrients are broadly adequate for the three Arctic cultures assessed: protein, carbohydrate, $n-3$ fatty acids, copper, iron, phosphorus, selenium, zinc, manganese, riboflavin and vitamin $\mathrm{B}_{6}$. The major dietary concerns for inadequacy reported here are for fibre, $n-6$ fatty acids, calcium, vitamin D, folate, vitamin A, vitamin C and vitamin E. To address these nutrition issues, we recommend enforcing several of the provisional dietary recommendations offered by Nobmann et al. ${ }^{10}$ for Alaskan Eskimos, as most are relevant to our results for Arctic First Nations and Inuit in Canada reported here and in our 
earlier papers. To improve on the extent of dietary adequacy for the nutrients of concern reported here, we recommend to Canadian Arctic communities and health professionals serving them to: (1) eat traditional meats and fish, and their organs for their high nutrient value and healthy fats; (2) encourage selection of purchased oils high in $n-6$ fatty acids and vitamin E for cooking and baking; (3) encourage carbohydrate foods with fibre, such as whole grains; (4) encourage consumption of dairy products, including yoghurt for those with lactose intolerance, to improve intakes of calcium, magnesium and vitamins A and D; (5) select whole vegetables and fruits regularly for vitamin $\mathrm{C}$ and folate, especially if families rely less on traditional, indigenous local meats and fish and their organs; (6) encourage exploration of traditional knowledge for earlier dietary sources of calcium and other seriously limited nutrients in diets of Arctic indigenous populations, conduct analyses on these foods, and encourage their use, if warranted; (7) importantly, with Arctic obesity increasing, we reiterate the principle in all North American dietary and food guidance - to balance energy intake from carbohydrates, proteins and fats (all food) with energy expenditure to prevent or reduce obesity and subsequent, associated chronic diseases.

\section{Conclusions}

Several nutrient issues are emerging for Canadian Arctic cultural groups with animal and fish food still relatively abundant, but consumed less frequently than in the past due to increased use of MF. This report identifies low usual group intakes of fibre, $n-6$ fatty acids, calcium, magnesium, vitamins $\mathrm{C}, \mathrm{D}$ and $\mathrm{E}$, and folate, although vitamin D was of less concern for older Inuit eating sea mammal meats and fats. Vitamin A was especially low for Dene/Métis, but less so for Yukon First Nations or Inuit. Protein, iron, copper, zinc, manganese, selenium, riboflavin and vitamin $\mathrm{B}_{6}$, as nutrients associated with meats and fish, were adequate for almost all age/gender groups. However, within these groups a few individuals exceeded ULs for iron, zinc, selenium, vitamin A and vitamin D.

It is understood that land and sea food resources of Arctic indigenous peoples are exceedingly important for cultural continuity and overall well-being, but these resources are also key to understanding nutritional status and how to improve it when needed. In this report, we show unusual patterns of intake for several essential nutrients. Recommendations for improving dietary adequacy must stress the value of maintaining availability and use of TF resources and improving availability and access to high-quality MF.

\section{Acknowledgments}

Sources of funding: This research was supported by the Canadian Institutes of Health Research (CIHR), Institute of Nutrition, Metabolism and Diabetes and Institute of Aboriginal Peoples' Health. We relied extensively for logistic and financial support upon Yukon Community Councils, Dene Community Councils, Métis Locals, Inuit Hamlet Councils, Hunters and Trappers Associations, the Labrador Inuit Association and the Inuvialuit Regional Corporation.

Conflict of interest declaration: There was no conflict of interest.

Authorship responsibilities: H.V.K. maintained overall responsibility for the research, O.R. was field supervisor, R.S. maintained data files, and P.R.B. completed statistical analysis.

Acknowledgements: We appreciate the work well done by our 16 CINE research coordinators and 97 trained interviewers. Laboratory support for the food composition database development was under capable supervision of Dr Laurie Chan and Donna Leggee and several students and staff members, as well as our collaborators in the Nutrition Division of Health Canada. Earlier on we had the very competent assistance of Annie May Propert, Marjolaine Boulay and Amy Ing. Special thanks to Dr Peter Fischer in Health Canada and all the DRI panelists, and particularly to Dr Alicia Carriquiry for guiding us through the analytical dietary assessment procedures with SIDE. For assistance in preparation of this manuscript, we thank Liz Ansell, Sandra Cohen and Dr Nelofar Athar.

We are greatly appreciative of the many collaborators we had during the entire research effort over the last 12 years. The project would not have been possible at all without the genuine concern, support and assistance from the aboriginal organisations and community leaders with whom we collaborated from the Council of Yukon First Nations, Dene Nation, Métis Nation (NWT), and the Inuit Tapiriit Kanatami. In particular, we thank Bill Erasmus, Ed Schultz, Norma Kassi, Cindy Dickson, Betsy Jackson, Barney Masuzumi, Carole Mills, William Carpenter, Rosemary Kuptana, Okalik Eegeesiak, Maryann Demmer, Peter Usher, Craig Boljkovak, Joanna Lampe, Frances Murphy and Eric Loring.

\section{References}

1 Kemp WB. Baffinland Eskimo. In: Damas D, ed. Arctic Handbook of North American Indians, Vol. 5. Washington, DC: Smithsonian Institution, 1984; 463-75.

2 Kutchin SR. In: Helm J, ed. Subarctic. Handbook of North American Indians, Vol. 6. Washington, DC: Smithsonian Institution, 1981; 514-32.

3 Kuhnlein HV, Receveur O, Chan HM. Traditional food systems research with Canadian Indigenous Peoples. International Journal of Circumpolar Health 2001; 60(2): 112-22.

4 Kuhnlein HV. Benefits and risks of traditional food for Indigenous Peoples: focus on dietary intakes of Arctic men. Canadian Journal of Physiology and Pharmacology 1995; 73(6): 765-71.

5 Kuhnlein HV, Receveur O, Soueida R, Egeland GM. Arctic indigenous peoples experience the nutrition transition with 
changing dietary patterns and obesity. Journal of Nutrition 2004; 134(6): 1447-53.

6 Kennedy G, Nantel G, Shetty P. Globalization of food systems in developing countries: a synthesis of country case studies. In: FAO Food and Nutrition Paper 83. Globalization of Food Systems in Developing Countries: Impact on Food Security and Nutrition. Rome: Food and Agriculture Organization of the United Nations, 2004; 1-26.

7 World Health Organization and Food and Agriculture Organization of the United Nations (WHO/FAO). Vitamin and Mineral Requirements in Human Nutrition, 2nd ed. Report of a Joint FAO/WHO Expert Consultation, Bangkok, Thailand. Geneva: WHO, 2004; 246-78.

8 Kuhnlein HV, Soueida R, Receveur OB. Inuit food use by age, gender and season. Journal of the Canadian Dietetic Association 1995; 56(4): 175-83.

9 Nakano T, Fediuk K, Kassi N, Egeland GM, Kuhnlein HV. Dietary nutrients and anthropometry of Dene/Métis and Yukon children. International Journal of Circumpolar Health 2005; 64(2): 147-56.

10 Nobmann ED, Ponce R, Mattil C, Devereux R, Dyke B, Ebbesson SO, et al. Dietary intakes vary with age among Eskimo adults of Northwest Alaska in the GOCADAN study, 2000-2003. Journal of Nutrition 2005; 135(4): 856-62.

11 Risica PM, Nobmann ED, Caulfield LE, Schraer C, Ebbesson SO. Springtime macronutrient intake of Alaska natives of the Bering Straits region: the Alaska Siberia project. International Journal of Circumpolar Health 2005; 64(3): 222-33.

12 Rejnmark L, Jorgensen ME, Pedersen MB, Hansen JC, Heickendorff L, Lauridsen AL, et al. Vitamin D insufficiency in Greenlanders on a westernized fare: ethnic differences in calcitropic hormones between Greenlanders and Danes. Calcified Tissue International 2004; 74(3): 255-63.

13 Nakano T, Fediuk K, Kassi N, Kuhnlein HV. Food use of Dene/Métis and Yukon children. International Journal of Circumpolar Health 2005; 64(2): 137-46.

14 Morrison NE, Receveur O, Kuhnlein HV, Appavoo M, Soueida R, Pierrot P. Contemporary Sahtú Dene/Métis use of traditional and market food. Ecology of Food and Nutrition 1995; 34(3): 197-210.

15 Fediuk K, Hidiroglou N, Madere R, Kuhnlein HV. Vitamin C in Inuit traditional food and women's diets. Journal of Food Composition and Analysis 2002; 15: 221-35.

16 Kuhnlein HV, Chan HM, Leggee D, Barthet V. Macronutrient, mineral and fatty acid composition of Canadian Arctic traditional food. Journal of Food Composition and Analysis 2002; 15: 545-66.

17 Kuhnlein HV, Barthet V, Farren A, Falahi E, Leggee D, Receveur O, et al. Vitamins A, D, and E in Canadian Arctic traditional food and adult diets. Journal of Food Composition and Analysis 2006; 19: 495-506.

18 Receveur O, Boulay M, Kuhnlein HV. Decreasing traditional food use affects diet quality for adult Dene/Métis in 16 communities of the Canadian Northwest Territories. Journal of Nutrition 1997; 127(11): 2179-86.

19 Sims J, Kuhnlein HV. Centre for Indigenous Peoples' Nutrition and Environment (CINE) and World Health Organization (WHO). Indigenous Peoples and Participatory Health Research: Planning and Management/Preparing Research Agreements. Geneva: WHO, 2003. Available at http://www.mcgill.ca/files/ cine/partresearch_english.pdf. Accessed 22 May 2007.

20 Kuhnlein HV, Receveur O, Muir DCG, Chan HM, Soueida R. Arctic indigenous women consume greater than acceptable levels of organochlorines. Journal of Nutrition 1995; 125(10): 2501-10.

21 Kuhnlein HV, Receveur O, Ing A. Energy, fat and calcium in bannock consumed by Canadian Inuit. Journal of the American Dietetic Association 2001; 101(5): 580-1.
22 Egeland GM, Berti P, Soueida R, Arbour LT, Receveur O, Kuhnlein HV. Age differences in vitamin A intake among Canadian Inuit. Canadian Journal of Public Health 2004; 95(6): 465-9.

23 Kuhnlein HV, Chan HM, Receveur O, Egeland G. Canadian Arctic indigenous peoples, traditional food systems and POPs. In: Fenge T, Downey D, eds. Northern Lights Against POPS: Combating Toxic Threats at the Top of the World. Montréal: McGill-Queen's University Press, 2002; $22-40$.

24 Appavoo D, Kubow S, Kuhnlein HV. Lipid composition of indigenous foods by the Sahtú (Hareskin) Dene/Métis of the Northwest Territories. Journal of Food Composition and Analysis 1991; 4: 107-19.

25 Kuhnlein HV, Appavoo D, Morrison N, Soueida R, Pierrot P. Use of nutrient composition of traditional Sahtú (Hareskin) Dene/Métis foods. Journal of Food Composition and Analysis 1994; 7: 144-57.

26 Kuhnlein HV, Kubow S, Soueida R. Lipid components of traditional Inuit foods and diets of Baffin Island. Journal of Food Composition and Analysis 1991; 4: 227-36.

27 Kuhnlein HV, Soueida R. Use and nutrient composition of traditional Baffin Inuit foods. Journal of Food Composition and Analysis 1992; 5: 112-26.

28 Morrison N, Kuhnlein HV. Retinol content of wild foods consumed by the Sahtú (Hareskin) Dene/Métis. Journal of Food Composition and Analysis 1993; 6: 10-23.

29 Kuhnlein HV. Nutrient benefits of Arctic traditional/country foods In: Kalhok S, ed. Synopsis of Research Conducted under the 2000-2001 Northern Contaminants Program. Ottawa: Minister of Indian Affairs and Northern Development, 2001; 56-64.

30 Murphy SP, Gross KR. The UCB Mini-List Diet Analysis System. MS-DOS Version User's Guide. Berkeley, CA: The Regents of the University of California, 1987.

31 Holden JM, Eldridge AL, Beecher GR, Buzzard IM, Bhagwat S, Davis C, et al. Carotenoid content of US foods: an update of the database. Journal of Food Composition and Analysis 1999; 12: 169-96.

32 Murphy SP. Changes in dietary guidance: implications for food and nutrient databases. Journal of Food Composition and Analysis 2001; 14: 269-78.

33 Nutrient Database for Standard Reference [database on the Internet]. USDA United States Department of Agriculture (USDA), Agricultural Research Service, Nutrient Data Laboratory. Available at http://nal.usda.gov/fnic/cgi-bin/ nut_search.pl. Accessed 13 January 2006.

34 Nusser SM, Carriquiry AL, Dodd KW, Fuller WA. A semiparametric transformation approach to estimating usual daily intake distributions. Journal of the American Statistical Association 1996; 91 : 1440-9.

35 Carriquiry AL. Assessing the prevalence of nutrient inadequacy. Public Health Nutrition 1999; 2(1): 23-34.

36 Carriquiry AL. Estimation of usual intake distributions of nutrients and foods. Journal of Nutrition 2003; 133(2): S601-8.

37 de Lauzon B, Volatier JL, Martin A. A Monte Carlo simulation to validate the EAR cut-point method for assessing the prevalence of nutrient inadequacy at the population level. Public Health Nutrition 2004; 7(7): 893-900.

38 Institute of Medicine; National Research Council. Dietary Reference Intakes: Applications in Dietary Assessment. Washington, DC: National Academy Press, 2000.

39 Institute of Medicine; National Research Council. Dietary Reference Intake for Vitamin A, Vitamin K, Arsenic, Boron, Chromium, Copper, Iodine, Iron, Manganese, Molybdenum, Nickel, Silicon, Vanadium, and Zinc. Washington, DC: National Academy Press, 2000.

40 Institute of Medicine; National Research Council. Dietary Reference Intake for Thiamin, Riboflavin, Niacin, Vitamin 
$B_{6}$, Folate, Vitamin B12, Pantothenic acid, Biotin, and Choline. Washington, DC: National Academy Press, 1998.

41 Institute of Medicine; National Research Council. Dietary Reference Intake for Calcium, Phosphorus, Magnesium, Vitamin D, and Fluoride. Washington, DC: National Academy Press, 1997.

42 Institute of Medicine; National Research Council. Dietary Reference Intake for Vitamin C, Vitamin E, Selenium, and Carotenoids. Washington, DC: National Academy Press, 2000.

43 Institute of Medicine; National Research Council. Dietary Reference Intake for Energy, Carbohydrate, Fiber, Fat, Fatty Acids, Cholesterol, Protein, and Amino Acids (Macronutrients). Washington, DC: National Academy Press, 2005.

44 Whiting SJ, Barabash WA. Dietary reference intakes for the micronutrients: considerations for physical activity. Applied Physiology, Nutrition, and Metabolism 2006; 31(1): $80-5$.

45 Institute of Medicine; National Research Council. Nutrient Adequacy: Assessment Using Food Consumption Surveys. Washington, DC: National Academy Press, 1986.

46 Murphy SP, Barr SI. Challenges in using the dietary reference intakes to plan diets for groups. Nutrition Reviews 2005; 63(8): 267-71.
47 Murphy SP, Guenther PM, Kretsch MJ. Using the dietary reference intakes to assess intakes of groups: pitfalls to avoid. Journal of the American Dietetic Association 2006; 106(10): 1550-3.

48 Kuhnlein HV, Receveur O. Local cultural animal food contributes high levels of nutrients for Arctic Canadian indigenous adults and children. Journal of Nutrition 2007; 137(4): 1110-14.

49 Petersen KM, Parkinson AJ, Nobmann ED, Bulkow L, Yip R, Mokdad A. Iron deficiency anemia among Alaska natives may be due to fecal loss rather than inadequate intake. Journal of Nutrition 1996; 126(11): 2774-83.

50 Yip R, Limburg PJ, Ahlquist DA, Carpenter HA, O'Neill A, Kruse D, et al. Pervasive occult gastrointestinal bleeding in an Alaska native population with prevalent iron deficiency. role of Helicobacter pylori gastritis. JAMA: Journal of the American Medical Association 1997; 277(14): 1135-9.

51 Hodgins S, Dewailly E, Chatwood S, Bruneau S, Bernier F. Iron-deficiency anemia in Nunavik: pregnancy and infancy. International Journal of Circumpolar Health 1998; 57(Suppl. 1): 135-40.

52 Christofides A, Schauer C, Zlotkin SH. Iron deficiency and anemia prevalence and associated etiologic risk factors in First Nations and Inuit communities in Northern Ontario and Nunavut. Canadian Journal of Public Health 2005; 96(4 Health Module): 304. 